\section{Pulp Chamber Heating: An In Vitro Study Evaluating Different Light Sources and Resin Composite Layers}

Lígia Maria Lima Andreatta ${ }^{1}$, Adilson Yoshio Furuse ${ }^{1}$, Anuradha Prakki², Juliana Fraga Soares Bombonatti ${ }^{1}$, Rafael Francisco Lia Mondelli ${ }^{1}$
'Department of Operative Dentistry, Endodotics and Dental Materials, Bauru Dental School, USP - Universidade de São Paulo, Bauru, SP, Brazil 2Department of Clinical Sciences (Restorative), Faculty of Dentistry, University of Toronto, Toronto, ON, Canada

Correspondence: Lígia Andreatta, Alameda Dr. Octávio Pinheiro Brisolla, 9-75, 17012-901 Bauru, SP, Brasil. Tel: +55-14-98114-3394. email: andreatta.ligia@gmail.com

Key Words: composites, temperature, pulp chamber.

\section{Introduction}

Resin composites are one of the aesthetic materials that most evolved in the last century and currently highlighted in dentistry for esthetic restorations. One of these developments was the replacement of benzoyl peroxide for camphorquinone (a light sensitive molecule), which allows the chain reaction polymer network formation to be initiated by light.

Nowadays, the most traditional devices in the market are based on quartz-tungsten-halogen (OTH) lamps and light emitting diodes (LED) and can be commercially found with different irradiances varying from $200 \mathrm{~mW} / \mathrm{cm}^{2}$ to 3200 $\mathrm{mW} / \mathrm{cm}^{2}$ (1). With the development of light sources and increase in irradiances, the warming in the pulp chamber started to be understood. These temperature increases may occur due to the exothermic reaction of the resin composite during polymerization or due to the energy emitted by the light source, which is absorbed by the restorative material during the light-activation (2). Thus, it is important to control the light-activation time with regards to the irradiance of the light source to allow the temperature increase inside the pulp chamber to remain within a safe range (3).

The classic studies of Lisanti and Zander (4) and Zach and Cohen (5) showed the concern with the internal temperature of the pulp chamber during dental procedures, which may lead to deleterious changes to the pulp tissue. Even today, despite the different results found in the past (6), the temperature increase during dental procedures still needs to be evaluated, especially when new high-irradiance LED-based devices are considered.

All new techniques, materials and equipment should be evaluated for their safety and effectiveness. Since the temperature increase may be related to the light source irradiance, exposure time and thickness of the resin composite (7), it becomes important to evaluate the change in the internal temperature of the pulp chamber when activating the adhesive system and increments of resin composite with different light sources. Thus, the aim of the present in vitro study was to evaluate the change in the internal temperature of the pulp chamber in bovine teeth due to light activation with different light sources in the adhesive layer and increments of resin composite. The following null hypotheses were evaluated: 1) no change will occur in the internal temperature of the pulp chamber due to the adhesive system and resin composite exothermic reaction of polymerization during 
light-activation with a OTH light source; 2) the different restorative steps while filling the cavity (adhesive system, first, second and third increments of resin composite) will not interfere in the temperature of the pulp chamber during the light-activation; 3) no change will occur in the internal temperature of the pulp chamber due to the irradiation with different light sources (LED low, LED high and QTH light); and 4) no change will occur in temperature regarding the light-activation time $(10,20,30$, and $40 \mathrm{~s})$.

\section{Materials and Methods}

\section{Study Design}

The present study evaluated different light sources (one factor in three levels). The change in the internal temperature of the pulp chamber in bovine teeth due to light activation was repeatedly measured in four periods (time in four levels) during the application of different increments of material (four levels: adhesive $[A D]$, first resin composite increment [1RC], second resin composite increment [2RC] and third resin composite increment [3RC]). The three light sources were: LD Max, Gnatus, Ribeirão Preto, SP, Brazil (Low LED); Elipar, 3M/ESPE, St. Paul, MN, USA (OTH), and VALO, Ultradent, South Jordan, UT, USA (High LED). The four periods were: $10 \mathrm{~s}, 20 \mathrm{~s}, 30 \mathrm{~s}$, and 40 s. Twelve groups were established $(n=10)$ according to the restoration step and the used light source.

\section{Specimen Preparation}

Ten bovine incisors with no fractures were selected and stored in a $0.1 \%$ thymol solution, until use. After cleaning, the teeth were sectioned at the root portion approximately $3 \mathrm{~mm}$ above the cementum/enamel junction with a \#3081 diamond bur (KG Sorensen, Barueri, SP, Brazil) in high speed under water irrigation. The root canal was enlarged with the same diamond bur. After sectioning, the pulp chamber and the remaining root of the teeth were cleaned by irrigation with saline. A palatal opening at the crown was made with \# 1014HL and \#3081 diamond burs (KG Sorensen), to enable the insertion of a gauge (Golgran, São Caetano do Sul, SP, Brazil) for measuring the remaining wall thickness of the axial dentin wall. Rectangular 10x8 $\mathrm{mm}$ cavities in the buccal face were prepared with a \# 1095 diamond bur and flatted with a \#1035 diamond bur. During flattening, the remaining thickness of the axial dentin wall was controlled with a gauge inserted into the openings of the buccal and palatal cavities. The remaining dentin of the axial cavity wall was standardized at $1.0 \mathrm{~mm}$.

After using the gauge, the palatal opening was restored with resin composite. The restoration was made with 37\% phosphoric acid (Condicionador Dental Gel; Dentsply Caulk, Petrópolis, RJ, Brazil), adhesive system (SBMP, Adper Scotchbond Multi-Purpose Adhesive; 3M/ESPESt. Paul, MN,
USA) and resin composite (Filtek Z250; 3M/ESPE, St. Paul, $M N$, USA), following manufacturer's instructions. The resin composite was inserted in a single step, sealing the cavity without invading the pulp chamber. The adhesive system and the resin composite light-activation occurred with a OTH light source for $40 \mathrm{~s}$ (Elipar 2500).

\section{Light Sources}

Before starting the light-activation, were checked the irradiances of the light sources. The power (in W or J/s) of each device was measured by placing and stabilizing the tip of the light source in close contact with a digital flatresponse power-meter (New Port - model 2936-R; Irvine, CA, USA). The spectral distributions of the lights were assessed by placing and stabilizing the tip on the light sensor of a spectrometer (Avantes, Apeldoorn, The Netherlands) connected to a computer running the Software Ava Soft 8.2.1. The diameter of the curing tip was checked with a digital caliper (Mitutoyo Absolute Digimatic, Kawasaki, Japan). The irradiances (in $\mathrm{mW} / \mathrm{cm}^{2}$ ) were obtained by dividing the power (in $\mathrm{mW}$ ) by the area of the curing tip. Graphs of irradiance and spectral distribution were plotted with Origin Pro 8.5. The irradiances were than calculated by dividing the measured power by the area of the curing tip. The obtained values were: Low LED $396.7 \mathrm{~mW} / \mathrm{cm}^{2}$, OTH Light $699.9 \mathrm{~mW} / \mathrm{cm}^{2}$, and LED VALO $1527.9 \mathrm{~mW} / \mathrm{cm}^{2}$. The spectral irradiance for Low LED, OTH and High LED is in Figure 1.

\section{Restoration of the $8 \times 10 \mathrm{~mm}$ Buccal Cavities}

The SBMP adhesive was applied after etching the teeth with 37\% phosphoric acid and three 1-mm-thick increments of Filtek Z250 were inserted. The thickness of these increments was measured and standardized with a millimeter probe (Golgran, São Caetano do Sul, SP, Brazil) in three points of the restoration: at the cavity cervical region, at the center and at the incisal region.

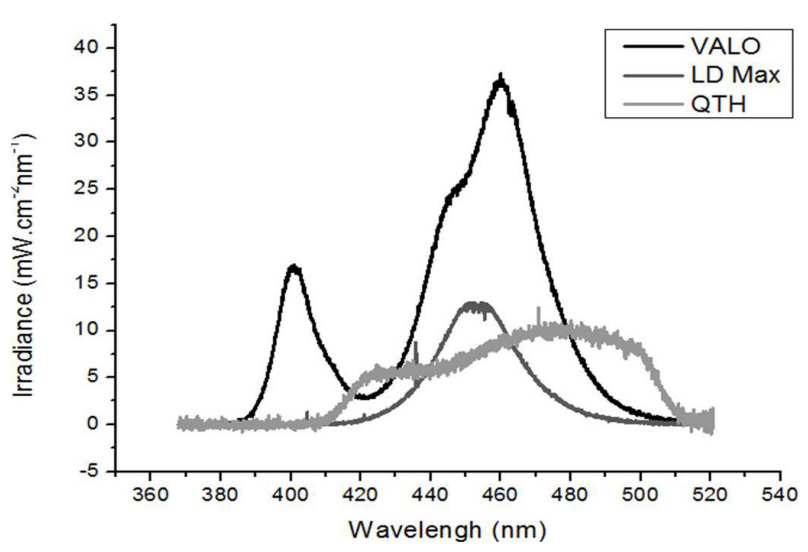

Figure 1. Spectral irradiance graph of the light sources devices. 


\section{Temperature Measurement}

The variation of pulp chamber temperature was measured with a K-type thermocouple sensor connected to a CPM-45 thermometer (Contemp, São Caetano do Sul, SP, Brazil). The thermocouple was inserted into the pulp chamber and placed in the center of the cavity in contact with the inner axial dentin wall (8-10). The sensor position was confirmed by the transparency of the axial dentin wall. A thermal paste (Implastec Eletrochemistry, Votorantim, SP, Brazil) was applied inside the pulp chamber. A thermal bath (BioPDI, São Carlos, SP, Brazil) with water at constant temperature at $37 \pm 1^{\circ} \mathrm{C}$ was used to maintain the temperature of the samples during the experiments. For this purpose the root portion of each tooth was attached to the water bath with a clamp to stabilize and maintain the specimen's root portion immersed in water.

The temperature was measured four times during the light-activation: at $10 \mathrm{~s}, 20 \mathrm{~s}, 30 \mathrm{~s}$ and $40 \mathrm{~s}$. At the end of the 40-s light activation, the internal temperature of the pulp chamber stabilized at $37 \pm 1^{\circ} \mathrm{C}$ again to start the light-activation with the next light source. The first light-activation was carried out with a OTH light (Elipar 2500), in continuous mode for $40 \mathrm{~s}$ with $699.9 \mathrm{~mW} / \mathrm{cm}^{2}$ irradiance. The tip of the device was as close as possible to the axial dentin wall. This first photoactivation with the QTH curing unit (OTH 1) aimed only to standardize the initial polymerization of the resin composite increments. The second light-activation was performed on the same specimen with the Low LED (LD Max) in continuous mode for $40 \mathrm{~s}$ with $396.7 \mathrm{~mW} / \mathrm{cm}^{2}$ irradiance. The third polymerization was carried out on the same specimen also with a LED device (VALO LED) in continuous mode for $40 \mathrm{~s}$ with $1527.9 \mathrm{~mW}$ / $\mathrm{cm}^{2}$ irradiance. The fourth polymerization was carried out on the same specimen with OTH light (Elipar 2500), used before, and now called (OTH 2), to standardize the initial polymerization of the composite and in continuous mode for $40 \mathrm{~s}$ with $699.9 \mathrm{~mW} / \mathrm{cm}^{2}$ irradiance.

After the consecutive use of all light sources for curing the adhesive, the first 1-mm increment was inserted, accommodated and light-activated in the same way cited above until the three increments of resin composite were completed and their corresponding temperature variations were recorded.

The heating related to the exothermic reaction of the adhesive system and of the three increments of resin composite was obtained by comparing the mean temperature values of the first light curing by the OTH light source on the uncured resinous material (OTH 1) and again on the already polymerized resin composite (OTH 2), after the use of the other light sources. The results were submitted to a normality test (Shapiro-Wilk's) and Equal Variance Test. Data were then analyzed with one-way
ANOVA with repeated measures. The post-hoc comparison was conducted with Tukey's test. A standard level of significance of was set at $5 \%$.

The heating due to light activation was obtained by comparing the mean temperature values in $40 \mathrm{~s}$ of light curing with the three light sources (Low LED, VALO and $\mathrm{OTH} 2$ ) and the four increments of material ( $A D, 1 R C$, $2 R C, 3 R C$ ). The results were submitted to a normality test (Shapiro-Wilk's) and Equal Variance Test. Data were than analyzed with one-way ANOVA with repeated measures. The post-hoc comparison was conducted with Tukey's test. A standard level of significance of was set at 5\%.

\section{Results}

Among the three light sources, the largest temperature increase occurred during the curing of the adhesive system, followed by the first increment of resin composite $(p<0.001)$. Regardless of the evaluated increment, the high power LED provided greater increase in temperature compared to QTH light and the low power LED (which showed less temperature variation in all restorative steps). While resin composite increments were added the intra pulp chamber warming decreased (from the adhesive to the first to the second and third increments). This difference was statistically significant for all light sources until the second increment of resin composite.

The mean values and standard deviations of heating from the first light-activation with OTH light device on uncured resin composite (OTH 1) and on the already lightactivated composite (OTH 2 ) are shown in Table 1. Statistical differences were significant only after the first increment of composite resin $(p<0.001)$.

The mean values and standard deviations of temperature for the three light sources used according to the four restorative steps (in the $40 \mathrm{~s}$ of light curing) are shown in Table 2.VALO promoted the greatest increase in temperature compared to the other light sources in all the tested restorative steps. The heating caused by the three light sources was statistically different for all and the low power

Table 1. Mean values and standard deviations of the exothermic reaction temperatures $\left(\right.$ in ${ }^{\circ} \mathrm{C}$ ) for the two light-activations with the same QTH light device (QTH 1 and QTH 2)

\begin{tabular}{lcccc}
\hline \multirow{2}{*}{$\begin{array}{l}\text { Light } \\
\text { Source }\end{array}$} & \multicolumn{4}{c}{ Increments } \\
\cline { 2 - 5 } & Adhesive & 1 RC & 2 RC & 3 RC \\
\hline QTH 1 & $40.93 \pm 0.92^{\mathrm{a}}$ & $40.50 \pm 0.21^{\mathrm{a}}$ & $39.14 \pm 0.54^{\mathrm{a}}$ & $38.42 \pm 0.93^{\mathrm{a}}$ \\
QTH 2 & $40.69 \pm 0.21^{\mathrm{a}}$ & $39.37 \pm 0.16^{\mathrm{b}}$ & $38.32 \pm 0.43^{\mathrm{b}}$ & $37.94 \pm 0.23^{\mathrm{b}}$ \\
\hline
\end{tabular}

Different letters in the same column indicate statistically significant differences, as evaluated by one-way Anova with repeated measures $(\mathrm{p}<0.001)$. 
LED showed the lowest temperature increase. The average temperature in each restorative step and time factors for the three light sources are in Figure 2. The power of the statistical tests was calculated of in all cases and indicated a $100 \%$ value.

\section{Discussion}

Curing resin-based restorative materials can increase the temperature and may cause damage to the dental pulp. This increase in temperature can be related to the used light source, the characteristics of the tooth substrate and the resin composite exothermic polymerization reaction (2). OTH lights are still used and LEDs are becoming the most used equipment in clinical practice. The increased irradiances of the newest light sources to reduce the irradiation time and increase the depth of curing (11) cause concerns regarding the heating of the inner pulp chamber. For this reason, different devices were chosen

Table 2. Temperature means and standard deviations $\left({ }^{\circ} \mathrm{C}\right)$ of the three light sources used according to the four restorative steps (40 s of light curing)

\begin{tabular}{|c|c|c|c|c|}
\hline \multirow{2}{*}{$\begin{array}{l}\text { Light } \\
\text { Source }\end{array}$} & \multicolumn{4}{|c|}{ Increments } \\
\hline & Adhesive & $1 \mathrm{RC}$ & $2 \mathrm{RC}$ & $3 \mathrm{RC}$ \\
\hline LED Low & $37.81 \pm 0.12^{\mathrm{aA}}$ & $37.66 \pm 0.11^{\mathrm{aB}}$ & $37.33 \pm 0.10^{\mathrm{aC}}$ & $37.26 \pm 0.11^{\mathrm{aC}}$ \\
\hline LED High & $42.78 \pm 1.56^{\mathrm{cA}}$ & $40.77 \pm 0.76^{\text {сВ }}$ & $39.35 \pm 0.69^{c c}$ & $38.75 \pm 0.42^{\mathrm{cC}}$ \\
\hline QTH 2 & $40.69 \pm 0.21^{\mathrm{bA}}$ & $39.37 \pm 0.16^{\mathrm{bB}}$ & $38.32 \pm 0.43^{\mathrm{bC}}$ & $37.94 \pm 0.23^{\mathrm{bC}}$ \\
\hline
\end{tabular}

Different lowercase letters in the same column indicate statistically significant differences $\mathrm{p}<0.001$ (light source factor). Capital letters in the same line indicate statistically significant differences $\mathrm{p}<0.001$ (restorative steps).

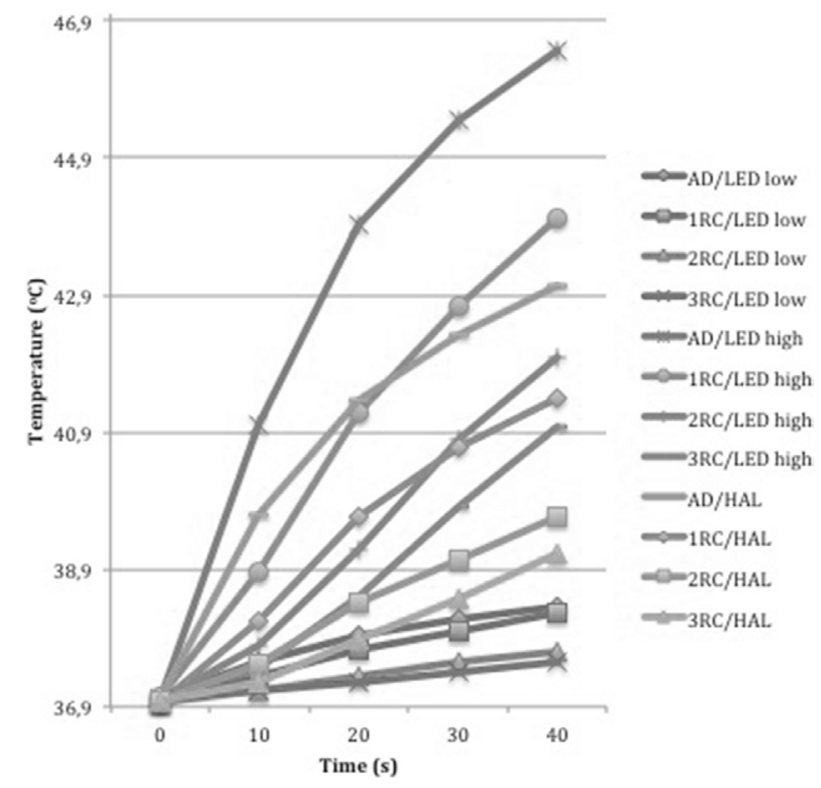

Figure 2. Temperature means of restorative steps and time factors for the three light sources. for the present study.

For the sake of better defining the irradiance ranges of light curing unit, in the present study, the irradiances and wavelength spectral distributions were evaluated with a power-meter and a spectrometer, respectively. This was conducted to ensure a more precise characterization of the devices. Irradiances were slightly different from those previously obtained with a regular radiometer. These differences are explained by the differences among tip diameters of the light curing units. It should be noted that although there were differences between measurements with the power-meter and the radiometer, the irradiances remained in the same order of range.

The evaluated adhesive system, maybe due to the thickness of the formed film (hybrid layer), showed no significant increase in average temperature related to the exothermic reaction. The average temperature of the three resin composite increments showed significant differences between the mean temperatures observed in both light sources (QTH 1 and QTH 2), causing an increase from the resin composite exothermic reaction of polymerization (Table 1) (12).

Curing the adhesive system, independent of the light source, caused the highest level of warming, followed by the first increment of resin composite. VALO showed the greatest increase in temperature, reaching the maximum temperature of $49.7^{\circ} \mathrm{C}$. These results possibly occurred because of the proximity of adhesive to the pulp chamber, as well as its thickness and reduced opacity, compared to the increments of resin composite. Higher temperature values during the adhesive curing were also found in the literature $(9,13)$.

Three consecutive increments of resin composite were used and standardized, respecting the ideal thickness values of $1 \mathrm{~mm}$ each (14). Heating was greater when the composite was thinner (first increment) (Table 2, Fig. $2)$, confirming the results of previous studies $(3,15,16)$. However, these results disagree with another study (9). These materials may have behaved as dispersive structure of the heat, hindering or preventing the produced heat (reaction+light) to reach the pulp chamber more efficiently. Thus, the null hypothesis regarding the restorative steps not interfering in the pulp chamber temperature during the filling of the cavity (adhesive system, 1RC, 2RC and $3 \mathrm{RC}$ ) was rejected, since there was a variation of intra pulp chamber temperature during the light-activation of the restorative steps for all tested light sources.

Regardless of the restorative step, light-curing with VALO and in some situations with OTH light (Elipar 2500), the heating exceeded $5.5^{\circ} \mathrm{C}$, considered critical to the pulp (5). In Yazici et al. (16), the $400 \mathrm{~mW} / \mathrm{cm}^{2}$ LED showed a lower 
temperature increase, probably due to its lower irradiance, similar to the results of the present study with the same LED irradiance. Choi et al. (3) comparing the irradiances of the light sources with an increase in temperature, observed that the use of a higher irradiance LED resulted in higher heating, confirming the results described herein.

The temperature increase was influenced by the light source, and the LED with high irradiance caused higher heating compared to QTH light and low LED, confirming the results obtained in other study (3). This may be due to the fact that the LED emits more specific wavelengths, closer to the absorption spectrum camphorquinone (17), often having a polymerization performance equal to or better than the OTH light (18). However, other authors comparing temperature changes with different photo-activation methods concluded that the QTH light source produced higher temperatures when compared to LED and Plasma Arc light sources (19). Therefore, the null hypothesis that there are no temperature variations related to the different light sources (low irradiance LED, high irradiance LED and QTH light) was rejected, since there was an increase of intra pulp chamber temperature for all tested light sources.

The effect of light curing time for the adhesive restorative materials has been studied (20). The curing time is controversial and there is generally an indication of $20 \mathrm{~s}$ by the manufacturer and 40 to $60 \mathrm{~s}$ by some authors, but the first $10 \mathrm{~s}$ is key for the absorption of photons by the initiator (21). Thus, regardless of the irradiance of the light sources, standardization ( $40 \mathrm{~s}$ ) occurred by the irradiation time and not by the radiated energy (J). Therefore, the null hypothesis that there is no temperature variation in function of polymerization time was also rejected because, regardless of the light source used, an intra pulp chamber progressive temperature was observed (Table 2, Fig. 2). These results indicate that the evaluated light sources, with the exception of the low irradiance LED, caused heating in the intra pulp chamber above the critical limit advised in the literature, requiring further studies for their use in clinical applications.

In the present study, only 10 teeth were used to decrease the bias related to dental anatomical variations and to allow a repeated measures design. Since the idea was to address the temperature variation caused by different light sources without considering variations in the remaining dentin thickness, size and volume of the restorative material, this design has proven to be an effective method of evaluating the already cured material. The standardization of $1 \mathrm{~mm}$ dentin thickness was done to simulate a critical situation in which the restoration is placed close to the dental pulp (16). The method employed in the present study was used in previous studies $(22,23)$ and the thermocouples inserted into the pulp chamber of bovine incisors provided reliable and accurate results when compared to human teeth (24). The effect of light on the cured and uncured composite is an important factor because after the polymerization, the material does not conduct the light in the same way as in its uncured form. However, it is well known that during the reaction of resin-based materials, the maximum reaction rate occurs in an early stage (a few seconds) after light activation (25). The maximum reaction rate is the moment in which the reaction kinetics of resin-based materials starts an auto-deceleration and there is an increase of the system's viscosity and decrease of chain flexibility. The decreased chain flexibility and consequent decreased molecular mobility probably decreases the heat transfer . Since the aim was to evaluate the difference between light sources to avoid the influence of heating caused by the exothermic reaction that occurs before the maximum reaction rate, the initial polymerization of all increments was done with the same QTH 1 light source to standardize the specimens in such a way that the final temperature measured was mainly related to the source and not the reaction itself. Thus, in the present study the heating related to the exothermic reaction was considered as the difference between OTH 1 and QTH 2.

In conclusion, the exothermic reaction of the resin composite provided a temperature increase to the resin composite increments, but not to the adhesive system. The high power LED provided the greatest increase in temperature compared to other light sources in all the restorative steps tested. The polymerization of the adhesive system followed by the first increment of resin composite determined the largest temperature increases, regardless of the light source used. Regardless of the light source and restorative step, the increase in the polymerization time was essential to temperature increase.

\section{Resumo}

0 objetivo do presente estudo in vitro foi avaliar a variação de temperatura dentro da câmara pulpar durante a fotoativação de um sistema adesivo e de camadas de resina composta com diferentes fontes de luz. Cavidades com dimensões de $8 \times 10 \mathrm{~mm}$ foram preparadas na superfície vestibular de incisivos bovinos deixando uma espessura de dentina remanescente de $1 \mathrm{~mm}$. Os espécimes foram inseridos em uma cuba térmica com água à temperatura de $37 \pm 1^{\circ} \mathrm{C}$. A temperatura no interior da câmara foi medida a cada $10 \mathrm{~s}$ durante $40 \mathrm{~s}$ de ativação de luz do sistema adesivo (SBMP; $3 \mathrm{M} / \mathrm{ESPE}$ ) e três camadas de $1 \mathrm{~mm}$ de espessura consecutivas de resina composta (Z250; 3M/ESPE ). Três fonte de luz foram avaliadas: Elipar 2500 (OTH), LD Max (LED de baixa densidade de potência), VALO (LED alta densidade de potência). Os resultados foram submetidos a ANOVA de medidas repetidas a um critério e teste de Tukey (ambos com $p<0,01$ ). 0 aquecimento da reação exotérmica foi observado nos incrementos de resina composta, mas não no sistema adesivo. 0 LED de alta densidade de potência mostrou uma média de temperatura mais elevada $(42,7 \pm 1,56$ $\left.{ }^{\circ} \mathrm{C}\right)$ seguido pela luz halogéna $\left(40,6 \pm 0,67^{\circ} \mathrm{C}\right)$ e o LED de menor densidade de potência $\left(37,8 \pm 0,12^{\circ} \mathrm{C}\right)$. Maiores aumentos de temperatura foram observados na fotoativação do sistema adesivo e do primeiro incremento de resina composta, independente da fonte de luz utilizada. A partir do segundo incremento de resina composta, o material restaurador agiu 
como estrutura dispersiva de calor, reduzindo o aumento de temperatura. Independente da fonte de luz e da etapa restauradora, a temperatura aumentou com o tempo de irradiação. Pode-se concluir que a fonte de luz, o tempo de irradiação, a espessura resina composta interferiram na variação de temperatura no interior da câmara pulpar.

\section{Acknowledgements}

The authors are indebted to Dr. Heitor Marques Honório from the Department of Pediatric Dentistry, Orthodontics and Public Health, Universidade de São Paulo, Bauru, SP for all the statistical analyses. The authors gratefully thank the assistance of Dr. Jose Humberto Dias da Silva from the Department of Physics, Univ. Estadual Paulista Júlio de Mesquita Filho, Bauru, SP, Brazil, and physicists Pedro D'Incao and Ulisses Antônio de Andreis from D'Incao educational institute, Bauru, SP, Brazil.

\section{References}

1. Jandt KD, Mills RW. A brief history of LED photopolymerization. Dent Mater 2013;29:605-617.

2. Knezevic A, Tarle Z, Meniga A, Sutalo J, Pichler G, Ristic M. Degree of conversion and temperature rise during polymerization of composite resin samples with blue diodes. J Oral Rehabil 2001;28:586-591.

3. Choi SH, Roulet JF, Heintze SD, Park SH. Influence of cavity preparation, light-curing units, and composite filling on intrapulpal temperature increase in an in vitro tooth model. Oper Dent 2014;39:195-205.

4. Lisanti VF, Zander HA. Thermal injury to normal dog teeth: in vivo measurements of pulp temperature increases and their effect on the pulp tissue. J Dent Res 1952 31;548-558.

5. Zach L, Cohen G. Pulp Response to Externally Applied Heat. Oral Surg Oral Med Oral Pathol 1965;19:515-530.

6. Baldissara P, Catapano S, Scotti R. Clinical and histological evaluation of thermal injury thresholds in human teeth: a preliminary study. J Oral Rehabil 1997;24:791-801.

7. Leprince J, Devaux J, Mullier T, Vreven J, Leloup G. Pulpal-temperature rise and polymerization efficiency of LED curing lights. Oper Dent 2010;35:220-230.

8. Rueggeberg F. Contemporary issues in photocuring. Compend Contin Educ Dent Suppl 1999;25:S4-15.

9. Godoy EdPPSK, Carvalho BM, Martins GC, Franco APGO. Lightcuring units: temperature rise induced through dentin and during polymerization of dental composites. Braz Oral Res 2007;3:11-20.

10. Millen C, Ormond M, Richardson G, Santini A, Miletic V, Kew P. A study of temperature rise in the pulp chamber during composite polymerization with different light-curing units. J Contemp Dent Pract 2007;8:29-37.

11. Guiraldo RD, Consani S, Sinhoreti MA, Correr-Sobrinho L, Schneider LF. Thermal variations in the pulp chamber associated with composite insertion techniques and light-curing methods. J Contemp Dent Pract 2009;10:17-24.

12. Rueggeberg FA, Caughman WF, Curtis JW, Jr. Effect of light intensity and exposure duration on cure of resin composite. Oper Dent 1994;19:26-32.

13. Loney RW, Price RB. Temperature transmission of high-output lightcuring units through dentin. Oper Dent 2001;26:516-520.

14. Yazici AR, Muftu A, Kugel G, Perry RD. Comparison of temperature changes in the pulp chamber induced by various light curing units, in vitro. Oper Dent 2006;31:261-265.

15. Burgess JO, Walker RS, Porche CJ, Rappold AJ. Light curing-an update. Compend Contin Educ Dent 2002;23:889-892, 894, 896.

16. Aleixo AR, Guiraldo RD, Fugolin AP, Berger SB, Consani RL, Correr $A B$, et al.. Evaluation of contraction stress, conversion degree, and cross-link density in low-shrinkage composites. Photomed Laser Surg 2014;32:267-273.

17. Schneider LF, Consani S, Sinhoreti MA, Sobrinho LC, Milan FM. Temperature change and hardness with different resin composites and photo-activation methods. Oper Dent 2005;30:516-521.

18. Elias ST, Santos AF, Garcia FC, Pereira PN, Hilgert LA, Fonseca-Bazzo YM, et al.. Cytotoxicity of universal, self-etching and etch-and-rinse adhesive systems according to the polymerization time. Braz Dent J 2015;26:160-168.

19. Chen $Y C$, Ferracane $J L$, Prahl SA. Quantum yield of conversion of the photoinitiator camphorquinone. Dent Mater 2007;23:655-664.

20. Martins GR, Cavalcanti BN, Rode SM. Increases in intrapulpal temperature during polymerization of composite resin. J Prosthet Dent 2006;96:328-331.

21. Savas S, Botsali MS, Kucukyilmaz E, Sari T. Evaluation of temperature changes in the pulp chamber during polymerization of light-cured pulp-capping materials by using a VALO LED light curing unit at different curing distances. Dent Mater J 2014;33:764-769.

22. Cavalcanti BN, Lage-Marques JL, Rode SM. Pulpal temperature increases with Er:YAG laser and high-speed handpieces. J Prosthet Dent 2003;90:447-451.

23. Furuse AY, Mondelli J, Watts DC. Network structures of Bis-GMA/ TEGDMA resins differ in DC, shrinkage-strain, hardness and optical properties as a function of reducing agent. Dent Mater 2011;27:497-506.

Received June 2, 2016 Accepted September 3, 2016 